\title{
Phosphorus in Our Waters
}

BY ADINA PAYTAN AND KAREN MCLAUGHLIN

\section{PURPOSES OF ACTIVITY}

- Familiarize students with the problem of nutrient loading and eutrophication.

- Encourage students to consider their own roles in humanecosystem interactions and also consider the ways that they could ameliorate the problem of cultural eutrophication of waters due to phosphorus loading from various anthropogenic sources.

- Expose students to analytical methods (standards, blanks, calibration curves).

- Exercise skills associated with field sampling (maintaining a field notebook, mapping, sample collection), statistics (e.g., replication of measurements, propagation of error, regressions), and reporting scientific data (tables, graphs).

\section{AUDIENCE}

The activity could be modified to fit a range of audiences from grade school students to beginning graduate students. It has been used in an introduction to oceanography class for college freshmen at Stanford University (nonscience majors) and for sixth-grade students.

\section{BACKGROUND}

What is phosphorus?

Phosphorus $(\mathrm{P})$ is an element that occurs naturally in rocks and soils. $\mathrm{P}$ is required by all living organisms (plants, animals, bacteria) for compounds associated with cell structure (phospholipids in membranes), nucleic acids (DNA), and energy (ATP). $\mathrm{P}$ is found in plant fertilizers, sewage from human and livestock waste, and in some household products such as toothpaste. $P$ use in detergents was banned in the 1970s. A major source of $\mathrm{P}$ in watersheds is agricultural runoff of excess fertil-

ADINA PAYTAN (apaytan@pangea.stanford.edu) is Assistant

Professor, Geological and Environmental Sciences, Stanford University, Stanford, CA. KAREN MCLAUGHLIN is Postdoctoral Researcher, University of California, Irvine. izer and livestock waste; P can then be transported from the land to streams and rivers and ultimately to lakes, estuaries, and coastal waters. Other sources of $\mathrm{P}$ pollution are industrial, manufacturing (paper pulp), and domestic land use (fertilizers applied to lawns and golf courses). When $P$ from any of these sources enters fresh- or marine-water bodies (ponds, lakes, estuaries), it becomes available to aquatic autotrophic organisms (algae, phytoplankton, and bacteria).

Why does too much phosphorus cause problems? Inorganic $\mathrm{P}$ is soluble in water and readily utilized by aquatic primary producers. The relative proportion of $\mathrm{H}_{2} \mathrm{PO}_{4}^{-}$, $\mathrm{HPO}_{4}^{2-}$, and $\mathrm{PO}_{4}^{3-}$ in solution depends on $\mathrm{pH}$ and salinity (see Ruttenberg, 2003). When $P$ enters rivers, lakes, and coastal waters, it stimulates the growth of aquatic primary producersphytoplankton, macroalgae, and sea grass - which require $\mathrm{P}$ for growth, as do land plants. The production of excess organic matter from the overload of anthropogenic $\mathrm{P}$ is called cultural eutrophication. If the primary producers are not eaten, they eventually sink to the deep water and sediment, where bacteria metabolize this organic matter and oxygen is consumed. When the concentration of biomass is large, the bacteria can consume most of the oxygen in the water, resulting in hypoxia (dissolved oxygen levels $<2 \mathrm{mg} \mathrm{L}^{-1}$ [or ppm]) or anoxia (oxygen depletion). Most animals become stressed at low oxygen concentrations, and in extreme cases this results in "dead zones"-areas where marine life cannot be supported due to depleted oxygen levels. The occurrence of dead zones is becoming more widespread as a result of increased anthropogenic nutrient pollution (e.g., see discussion in Rabalais, 1998).

\section{RESEARCH QUESTIONS}

How much $\mathrm{P}$ is contained in water from streams, rivers, lakes, or bays? What are the potential sources of this $\mathrm{P}$ ? Are $\mathrm{P}$ concentrations in receiving waters related to the source of the water or anthropogenic activities in the watershed?

As part of the "invitation stage" of the activity, ask students 
to predict/guess what the relative $\mathrm{P}$ concentrations of the samples they collected are and to explain why they predict this distribution (note that they don't have to be correct at this stage).

\section{HYPOTHESIS}

Sewage- and fertilizer-polluted waters will have high P concentrations compared to pristine "clean" water sources.

\section{MATERIALS}

\section{Lab Equipment Preparation}

- Acid bath for washing all of the bottles, flasks, test tubes, etc.

- Cleaning acid-10\% $\mathrm{HCl}$

All of the equipment used should be acid washed in advance: Soak in $10 \% \mathrm{HCl}$ acid bath for 24 hours, rinse three times with Milli-Q water, and air dry.

\section{Standards Preparation}

- P standard solution (see preparation instructions below)

- Volumetric flasks (1000 ml, $100 \mathrm{ml}$, and $50 \mathrm{ml}$, acid washed)

- Graduated cylinders (100 ml, acid washed)

- Bottles (plastic $100 \mathrm{ml}$, acid washed) or volumetric flasks for storing the standards

- Milli-Q water (purified by ion exchange) or distilled water for standards, blank, and dilutions

- Gloves, safety goggles

\section{Field Work}

- Field notebook, map, and GPS

- Bucket or water-sampling bottle (Van Dorn, Niskin, etc.)

- Bottles (plastic $100 \mathrm{ml}$, acid washed) for sample collection

- Syringes $60 \mathrm{ml}$ (disposable plastic syringe with Luer-Lok tip and plastic plunger that could be attached to an in-line filter such as Fisher Scientific 14-841-36 or equivalent)

- Syringe filters $(0.45 \mu \mathrm{m}, 25 \mathrm{~mm}$, Cellulose Acetate, ColeParmer EW-02915-58 or equivalent) to fit syringes

- Labeling tape and waterproof markers for labeling sample bottles

- Cooler for sample storage and transport

\section{Sample Analyses}

- Spectrophotometer (if possible with wavelength range into the near infrared [IR])

- Spectrophotometer cells (1-cm path length for high concen- trations, $10-\mathrm{cm}$ path length for low concentrations)

- Standard P solutions (diluted from stock P standard solution-see preparation instructions below)

- Ready-made reagent packs (e.g., Phosver 3 reactant powder pillows: HACH-Permachem Reagent Cat. 21060-69, Aquatic Life PL 412 reagent pack, or equivalent) or a mixed reagent solution (see preparation instructions below)

- Test or centrifuge tubes (50 ml with cap, acid washed) for mixing the samples with the reagent

- 5-ml and 1-ml automatic pipettes and pipette tips

- Water samples (collected by the students on a field trip)

- Timer

- Waste bottle for disposal of used reagents

- Kimwipes for wiping test tubes

- Gloves, safety goggles

- Material Safety Data Sheets (MSDS)

\section{ACTIVITY}

\section{Sample Collection}

Take the students on a field trip to collect samples from various locations. The collection sites should represent a wide range of water samples with different $\mathrm{P}$ concentrations (the instructor must select and check the sites and determine expected $\mathrm{P}$ concentrations in advance). Samples should be collected from natural and impacted (sewage outfall) locations, and may include fresh and/or salt water, rain and/or tap water, garden runoff, irrigation-ditch samples, and samples from streams, lakes, and estuaries.

In the field, locate and mark the collection site on a local map (use GPS) and list the information in the field notebook (date, time, location, water depth, site description, sample number, etc.). Collect water using a bucket or a water-sampling bottle (Van Dorn, Niskin, etc.). Filter the water on site using the $0.45 \mu \mathrm{m}$ syringe filter to remove particulate matter that may interfere with the analysis). Draw water into the syringe and rinse three times; refill, attach filter unit to syringe, and squirt $\sim 10 \mathrm{ml}$ to rinse the filter. Rinse the prelabeled, acid-washed sample bottle three times and fill two-thirds full. Rinsing lowers risk of contamination. Store samples in a cooler while in the field; analyze or freeze upon return to the lab. If you can collect other data, such as temperature of the water and salinity, do so; specifically, try to get some measure of the biomass in the water (e.g., chlorophyll) or visually estimate the biomass content. The 
latter is important in cases where the $\mathrm{P}$ was already consumed and converted to biomass.

Ideally, the water samples will be collected with the students on a field trip to a local watershed. If this is not possible, students can be asked to each bring a water sample to class (encourage them to bring a wide range of samples and give examples). Samples could also be collected by the teacher or "mock samples" (water with $\mathrm{P}$ added) can even be prepared ahead of time if no real samples can be used. Make sure to test the samples before using them, particularly if you are using a detergent to demonstrate anthropogenic $\mathrm{P}$ sources, because many detergents do not have high $\mathrm{P}$ concentrations.

\section{Experiment}

The $\mathrm{P}$ concentration in the water samples will be determined to assess whether concentrations are related to land use in the watershed from which they were collected. In addition, P concentrations in tap water, fertilizer (dissolved in water or clear liquid fertilizer), sewage-treatment water, and a detergent or toothpaste sample dissolved in water (potential sources) could be analyzed. Test samples and dilutions in advance.

Caution: The molybdate solution used in this analysis is a strong acid (2.5 $\mathrm{N} \mathrm{H}_{2} \mathrm{SO}_{4}$ ) and should be treated accordingly. Everyone must wear safety glasses and gloves. All surfaces (especially in and on the spectrophotometer) should be wiped clean after analysis, and all spills (no matter how small) should be cleaned up immediately.

\section{PROCEDURE}

\section{Preparing Standards}

Prepare five standards $(10 \mu \mathrm{M}, 5 \mu \mathrm{M}, 3 \mu \mathrm{M}, 1 \mu \mathrm{M}, 0.5 \mu \mathrm{M}$ - see Table 1 for instructions) of $100 \mathrm{ml}$ each from the standard $\mathrm{P}$ solution (by serial dilutions) using the graduated cylinders or automatic pipette. Transfer standards to dry, labeled, acidwashed bottles or 100-ml volumetric flasks.

Please note that it is better to prepare the standards gravimetrically (by weight), but with a class it is simpler and faster to do it by volume. You may want to discuss this in class, depending on the level and background of the students.

\section{Producing a Calibration Curve}

1. Add $10 \mathrm{ml}$ of blank or $10 \mathrm{ml}$ of each of the standards to each of three test or centrifuge tubes (three replicates).
Table 1. Dilutions for preparing standards

\begin{tabular}{|l|l|l|}
\hline $\begin{array}{l}\text { Standard } \\
\text { Concentration } \\
(\mu \mathrm{M})\end{array}$ & $\begin{array}{l}\text { Standard } \\
\text { Solution } \\
(\mathrm{ml})\end{array}$ & $\begin{array}{l}\text { Milli-Q } \\
\text { Water } \\
(\mathrm{ml})\end{array}$ \\
\hline $10 \mu \mathrm{M}$ & $1 \mathrm{ml}$ of stock solution & $99 \mathrm{ml}$ \\
\hline $5 \mu \mathrm{M}$ & $50 \mathrm{ml}$ of $10 \mu \mathrm{M}$ & $50 \mathrm{ml}$ \\
\hline $3 \mu \mathrm{M}$ & $30 \mathrm{ml}$ of $10 \mu \mathrm{M}$ & $70 \mathrm{ml}$ \\
\hline $1 \mu \mathrm{M}$ & $10 \mathrm{ml}$ of $10 \mu \mathrm{M}$ & $90 \mathrm{ml}$ \\
\hline $0.5 \mu \mathrm{M}$ & $10 \mathrm{ml}$ of $5 \mu \mathrm{M}$ & $90 \mathrm{ml}$ \\
\hline Blank & No standard solution & $100 \mathrm{ml}$ water \\
\hline
\end{tabular}

2. Add the prepacked reagent to each tube (follow manufacturer's directions for quantity) or $1 \mathrm{ml}$ of mixed reagent (which includes the reducing agent—see reagent preparation instructions below).

3. Cover and shake immediately for 15 seconds.

4. Set the timer for at least 5 minutes to allow for color to develop (watch as color develops). The time from reagent addition to analysis in the spectrophotometer can be flexible as long as it is less than 30 minutes and each sample is allowed to react for the same length of time.

5. Set the spectrophotometer to the appropriate program (follow spectrophotometer instructions) and the detector to the appropriate wavelength (typically in the near IR range, $885 \mathrm{~nm}$ ).

6. Use Milli-Q water to zero the spectrophotometer.

7. After five minutes (and within 30 minutes), transfer standard solutions and blank to the spectrophotometer cell (1-ml cell is good for the high-concentration samples, but 10-ml may be needed for lower concentrations), wipe optical surfaces to avoid fingerprints, read absorbance, and record in a table (see example data sheet). Subtract the absorbance of the blank from each of the standards.

8. Plot the calibration curve on a graph with concentration on the $\mathrm{x}$ axis and absorbance on the $\mathrm{y}$ axis (see Figure 1). Fit a linear curve to your data and determine the relation between absorbance and concentration. This is expressed as an equation in the form:

$$
y=a x+b \text {, }
$$

where $y$ is absorbance, $x$ is concentration, $a$ is the slope, and $b$ is the $y$-intercept. Note: One indicator of the quality of 


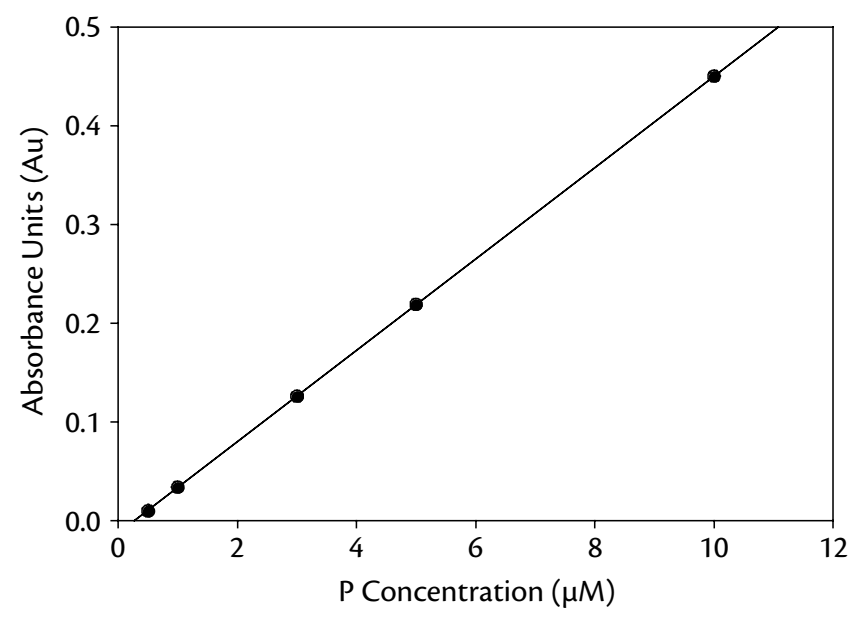

Figure 1. Calibration curve for determining phosphorus content in water samples.

your calibration curve is the size of $b$. It should be a very small value if the regression line passes through or near the origin. The correlation coefficient, $r$, indicates how closely the data points match (or fit) the regression line value of 1.00 (e.g., best fit). Try without subtracting blank.

This relationship between concentration and absorbance of the standards will then be used to determine the concentration of your samples.

\section{Analyzing the Samples}

1. Pipette $10 \mathrm{ml}$ of each sample into each of three test or centrifuge tubes (three replicates). Make sure the samples are at room temperature before adding the reagent.
2. Add the prepacked reagent to each tube (follow manufacturer's directions for quantity) or $1 \mathrm{ml}$ of mixed reagent (which includes the reducing agent—-see reagent preparation instructions below).

3. Shake immediately for 15 seconds, and set the timer for 5 minutes (this time can be flexible as long as it is less than 30 minutes and each sample reacts for the same length of time).

4. Transfer sample and reagent mixture to the spectrophotometer cell (1-ml cell is good for the high concentration samples, but 10-ml is needed for lower concentrations), wipe optical surfaces to avoid fingerprints, read absorbance, and record in a table (see example data sheet). Any samples that exceed the calibration working range need to be diluted to fit the calibration working range and reanalyzed.

5. Subtract the absorbance of the blank from that of each sample.

6. Calculate the $\mathrm{P}$ concentration in each sample $(\mu \mathrm{M})$ from its absorption and equation 1. Calculate the mean and standard deviation for the $\mathrm{P}$ concentrations for each sample from your triplicates. If the lab is done by different small groups, also compare the data for each sample among groups.

\section{WHAT'S HAPPENING}

The $\mathrm{P}$ concentration is determined by treating an aliquot of sample with an acidic molybdate reagent containing ascorbic acid and potassium antimonyl tartrate. In an acidic solution, $\mathrm{P}$ forms a yellow complex with molybdate, which is slowly

\section{BOX 1. IMPORTANT TERMS TO DEFINE FOR/WITH THE CLASS}

STATISTICS: Standard deviation, detection limits, precision, accuracy, reproducibility, and other statistical terms. Provide definitions for these and other relevant terms along with explanations about elementary concepts in statistics, basic statistics, and linear regression. A statistical glossary and relevant references can be found online at: http://www.statsoft.com/textbook/stathome.html.

BEER'S LAW: A physical law stating that the quantity of light absorbed by a substance dissolved in a nonabsorbing solvent is directly proportional to the concentration of the substance and the path length of the light through the solution. Beer's Law is commonly written in the form $A=\varepsilon \mathrm{cl}$, where $\mathrm{A}$ is the absorbance, $\mathrm{C}$ is the concentration in moles per liter, $I$ is the path length in centimeters, and $\varepsilon$ is a constant of proportionality known as the molar extinction coefficient ( $\mathrm{SI}$ units of $\mathrm{m}^{2} \mathrm{~mol}^{-1}$ ). The law is accurate only for dilute nonscattering solutions; deviations from the law occur in concentrated solutions because of interactions between molecules of the solute, the substance dissolved in the solvent. For conditions where Beer's Law applies, a plot of absorbance against concentration will give a straight line (see Figure 1), the slope of which is $\varepsilon$ I. 


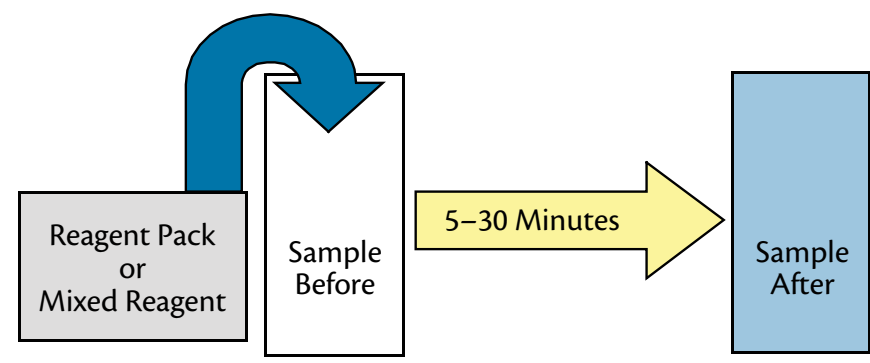

Figure 2. The sample turns blue with the addition of the mixed reagents.

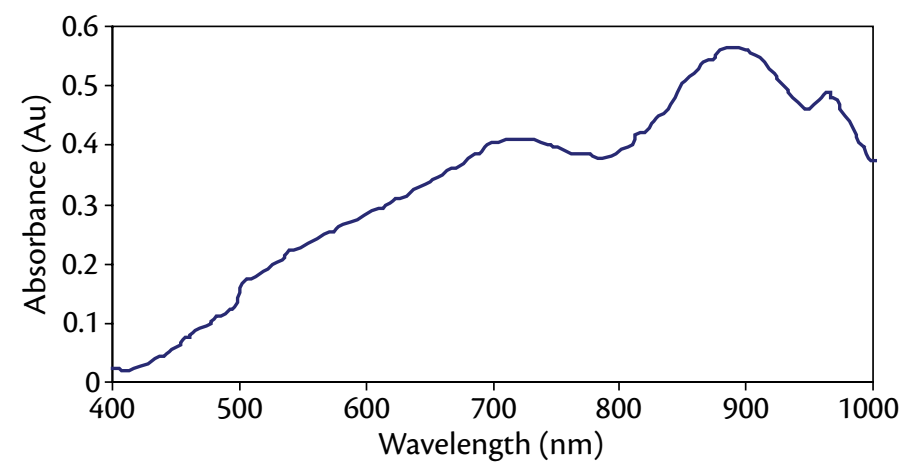

Figure 3. The absorption spectra of the antimony-phosphomolybdate complex.

reduced by the ascorbic acid. Antimony speeds the reaction process to form an antimony-phospho-molybdate complex, which has a blue color (Figure 2). The absorbance of this solution is measured at $\sim 885 \mathrm{~nm}$ with a spectrophotometer.

The more $P$ present in the sample, the darker blue the sample will become, but also the greater will be the absorption by the antimony-phosphomolybdate complex at $885 \mathrm{~nm}$ (Figure 3).

The absorption curve of antimony-phosphomolybdate (Figure 3 ) shows that the complex absorbed least in the blue light $(492-455 \mathrm{~nm})$ range, resulting in the blue color of the solution. The maximum absorp-

tion is in the near IR range, around $885 \mathrm{~nm}$. Therefore, using a spectrophotometer that has an IR detector is desirable to increase the sensitivity of the analysis. However, if such a spectrophotometer is not available, it is possible to use one with a visible-light detection range focusing on the red wavelength around $700 \mathrm{~nm}$ and compromising some sensitivity. The spectrophotometer mea- sures quantitatively the fraction of light that passes through the solution. In the spectrophotometer used here, the initial light source emits all wavelengths, but only the target wavelength $(885 \mathrm{~nm})$ passes through a diffraction grating and then through the sample. The detector measures the intensity of the remaining light (Figure 4). The amount of IR light absorbed by the sample is proportional to the $\mathrm{P}$ concentration and is converted to concentration in $\mu \mathrm{M}$ of $\mathrm{P}$ in the solution using the calibration curve.

\section{POSSIBLE MODIFICATIONS}

If you do not have a spectrophotometer available, you can get relative $\mathrm{P}$ concentrations just by observing the darkness of the blue color. The antimony-phosphomolybdate scatters the blue light most effectively and thus the solution has a blue color. The higher the $\mathrm{P}$ concentration, the darker the blue. This procedure will not give quantitative $\mathrm{P}$ concentrations, but is fine for relative comparison. It is also possible to make a color wheel with different shades of blue (using pictures of the results from standards) and assigning concentrations to these colors; the color for each sample is then compared to this scale.

\section{RESULTS}

Data should be reported in a table (see example) that includes the sample number, sample type or location, absorbance, and the $\mathrm{P}$ concentration in the sample as well as the mean and standard deviation for the triplicates. Data could also be plotted as a bar diagram. A local watershed map, ideally with land-use information and sample numbers marked at the collection locations, should be prepared.

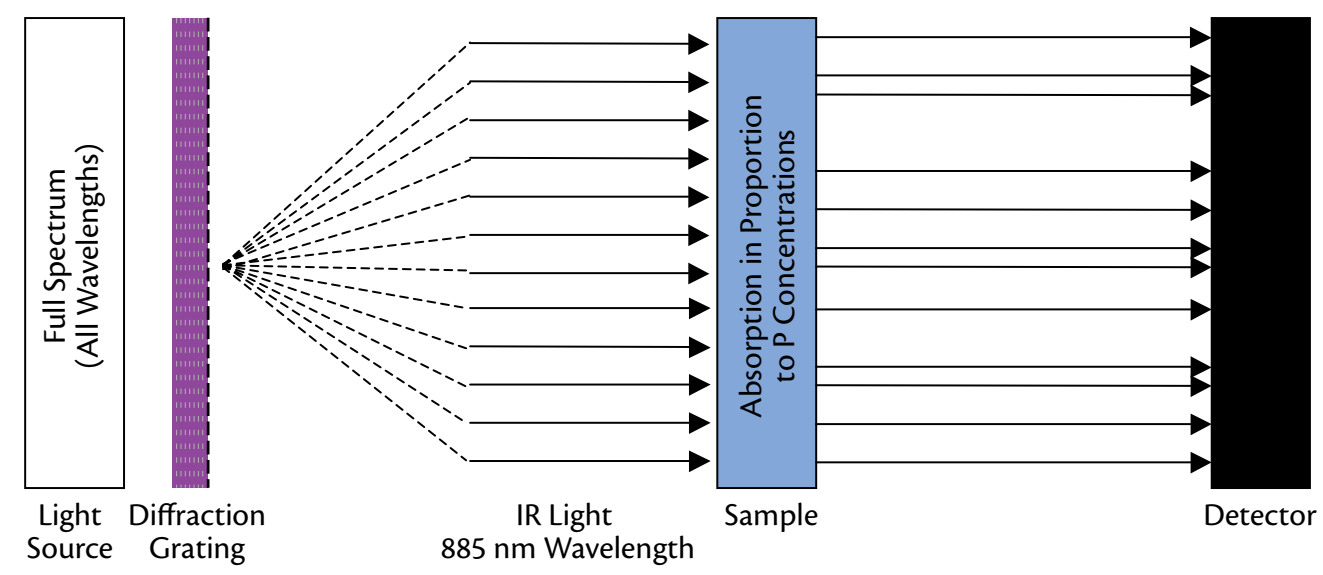

Figure 4. Schematic diagram of what happens in the spectrophotometer. 


\section{DISCUSSION}

When analyzing the data, students will have to think about what affects the water chemistry at each of the sites. Compare the different concentrations of $\mathrm{P}$ in each sample. Discuss where the samples came from and why some have more P than others. Note that it is possible that the $\mathrm{P}$ is effectively utilized by the biomass in the water body (lake, estuary, coast). In that case, the $\mathrm{P}$ concentration may actually be low. You can discuss the relationship between biomass and $\mathrm{P}$ input rather than $\mathrm{P}$ concentrations.

\section{Discussion Questions}

1. What is a nutrient? (Element or compound required by the organism)

2. Where do you think nutrients come from? (Soil and rocks, fertilizers, sewage, upwelling) How do they get to the ocean? (By runoff, rivers, and groundwater)

3. Based on the data you collected, which location do you think will have the highest abundance of phytoplankton? (All else being equal, that with the highest nutrients, including $\mathrm{P}$ ) Which will have the smallest? (That with lower nutrient concentrations). Why? (Phytoplankton need nutrients in addition to light for growth).

4. What if the phytoplankton have used all of the $\mathrm{P}$ in the water? (They could utilize organic $P$ forms, effectively recycle the $\mathrm{P}$, or stop growing) What if another essential nutrient like nitrogen is utilized to completion before all the $\mathrm{P}$ is taken? (The organisms will not be able to use up all the $\mathrm{P}$ their growth will be limited by nitrogen)

5. What do you think might be the largest source of $P$ to the bay/coast/estuaries? (This depends on the P concentration in each potential source and the input flux of that source-for example: sewage-treatment water may have more P, but contribute less water then the river)

6. Why does the receiving water body have less $\mathrm{P}$ than the river and sewage waters? (Dilution and uptake)

7. What is the relation between $\mathrm{P}$ and other essential nutrients? (The concentration in the water of the various nutrients will depend on their relative input and utilization by the organisms. Redfield ratios could be discussed here)

8. What can we do to prevent $\mathrm{P}$ eutrophication? (Reduce P use and disposal into environmental water)
Discuss the calibration curves, the need for blanks, standards, Beer's Law, standard addition procedures and other calibration methods as well as issues of reproducibility, accuracy, and standard-deviation calculations.

\section{GENERAL COMMENTS}

This activity was used in an introductory oceanography undergraduate class (The Ocean Around Us) that emphasizes human-ocean interaction. San Francisco Bay was used and samples were collected from the Sacramento River, a sewage treatment plant outfall, the Pacific Ocean, and two locations within the bay. Students worked in teams ( 3 to 4 students).

\section{RELATED TOPICS FOR FUTURE INVESTIGATIONS}

If you are teaching chemical oceanography and want to include such an activity, it is easy to substitute the samples to represent (1) central gyre surface waters, (2) surface water in an upwelling area, (3) North Atlantic deep water, (4) South Atlantic deep water, and (5) North Pacific deep water. The discussion then will center on nutrient distribution in the ocean and the processes that impact this distribution (uptake, regeneration, accumulation along the "conveyer belt"). Other elements or compounds can also be used for specific sites, depending on analytical capabilities (nitrate, mercury, etc.) ש

\section{REFERENCES}

Rabalais N.N. 1998. Oxygen depletion in coastal waters. In NOAA's State of the Coast Report. Silver Spring, MD. Available online at: http://oceanservice. noaa.gov/websites/retiredsites/sotc_retired.html (accessed March 8, 2007). Ruttenberg, K.C. 2003. The global phosphorus cycle. Chapter 13 in Treatise on Geochemistry, Volume 8, W.H. Schlesinger, ed, Elsevier.

\section{ADDITIONAL LITERATURE}

Grasshoff, K., M. Ehrhardt, and K. Kremling, eds. 1983. Methods of Seawater Analysis. Verlag Chemie. NY, 419 pp.

Schlesinger, W.H. 1997. Biogeochemistry: An Analysis of Global Change. Academic Press, San Diego, CA, especially pages 396-398.

\section{ADDITIONAL ONLINE RESOURCES}

http://wwwchem.uwimona.edu.jm/lab_manuals/c10expt36.html http://www.enviroliteracy.org/article.php/480.html http://toxics.usgs.gov/definitions/hypoxia.html 


\section{COMBINED REAGENT PREPARATION}

Ammonium molybdate solution: Dissolve $40 \mathrm{~g}$ of ACS grade ammonium heptamolybdate (synonyms: ammonium paramolybdate or hexaammonium molybdate; $\left.\left[\left(\mathrm{NH}_{4}\right)_{6} \mathrm{M} \mathrm{o}_{7} \mathrm{O}_{24} \cdot 4 \mathrm{H}_{2} \mathrm{O}\right]\right)$ into $800 \mathrm{ml}$ Milli-Q water and dilute to $1 \mathrm{~L}$ in a volumetric flask. Store in a plastic bottle in the dark. Solution is stable indefinitely.

Ascorbic acid solution (prepare fresh or freeze and thaw immediately before use): Dissolve $1.8 \mathrm{~g}$ of ACS ascorbic acid into $100 \mathrm{ml}$ Milli-Q water (1.8\% $\mathrm{wt} / \mathrm{vol}$ ), using either a volumetric flask or a graduated cylinder. This solution is stable for months if kept frozen.

Antimony potassium tartrate solution: Dissolve $3.0 \mathrm{~g}$ of ACS antimony potassium tartrate $\left(\mathrm{C}_{8} \mathrm{H}_{4} \mathrm{~K}_{2} \mathrm{O}_{12} \mathrm{Sb}_{2} \cdot 3 \mathrm{H}_{2} \mathrm{O}\right)$ into $800 \mathrm{ml}$ Milli-Q water and dilute to $1 \mathrm{~L}$ in a volumetric flask. Solution is stable for several months.

Mixed reagent (prepare fresh): Mix together in the following order $15 \mathrm{ml}$ ammonium molybdate, $50 \mathrm{ml} 5 \mathrm{~N}$ sulfuric acid, $30 \mathrm{ml} 1.8 \%$ ascorbic acid, and $5 \mathrm{ml}$ potassium antimony tartrate. Shake the solution thoroughly and store in plastic bottles. Make a fresh mixture on the morning of each lab day. A mixed reagent solution made with all reagents except ascorbic acid is stable and can be stored in the refrigerator; freshly prepared ascorbic acid can then be added to this mixture before use.

Stock P standard solution ( $1 \mathrm{mM}$ ): Dissolve $0.1361 \mathrm{~g}$ of dry potassium $\mathrm{P}$ monobasic $\left(\mathrm{KH}_{2} \mathrm{PO}_{4}\right.$ oven dried and cooled in a desiccator prior to weighing) into $800 \mathrm{ml}$ of Milli-Q water and dilute to $1 \mathrm{~L}$ in a volumetric flask. Store the standard in a dark bottle in the refrigerator. Use this solution to prepare the calibration standard solutions (for example, the $10 \mu \mathrm{M}$ is prepared by diluting this stock solution 1:100 with Milli-Q water). Alternatively a P standard can be purchased from most scientific supply companies (e.g., Fisher Scientific, VWR) and used to make the calibration standards.

Reagents and the $\mathrm{P}$ stock solution $(1 \mathrm{mM})$ should also be prepared in advance and refrigerated.

Example Data Sheet

\begin{tabular}{|l|l|l|l|l|l|}
\hline $\begin{array}{l}\text { Sample } \\
\text { Number }\end{array}$ & $\begin{array}{l}\text { Sample Description } \\
(\text { Lat/Long) }\end{array}$ & Absorbance & Concentration $(\boldsymbol{\mu M})$ & Mean $(\mathbf{n}=\mathbf{3})$ & Standard Deviation \\
\hline Sample 1a & $\begin{array}{l}\text { Rain Water } \\
\left(37^{\circ} 30^{\prime} \mathrm{N}, 122^{\circ} 20^{\prime} \mathrm{W}\right)\end{array}$ & & & \\
\hline Sample 1b & $\begin{array}{l}\text { Rain Water } \\
\left(37^{\circ} 30^{\prime} \mathrm{N}, 122^{\circ} 20^{\prime} \mathrm{W}\right)\end{array}$ & & & \\
\hline Sample 1c & $\begin{array}{l}\text { Rain Water } \\
\left(37^{\circ} 30^{\prime} \mathrm{N}, 122^{\circ} 20^{\prime} \mathrm{W}\right)\end{array}$ & & & \\
\hline Sample 2a & $\begin{array}{l}\text { S.J. River Water } \\
\left(38^{\circ} 10^{\prime} \mathrm{N}, 121^{\circ} 60^{\prime} \mathrm{W}\right)\end{array}$ & & & \\
\hline Sample 2b & $\begin{array}{l}\text { S.J. River Water } \\
\left(38^{\circ} 10^{\prime} \mathrm{N}, 121^{\circ} 60^{\prime} \mathrm{W}\right)\end{array}$ & & & & \\
\hline Sample 2c & $\begin{array}{l}\text { S.J. River Water } \\
\left(38^{\circ} 10^{\prime} \mathrm{N}, 121^{\circ} 60^{\prime} \mathrm{W}\right)\end{array}$ & & & \\
\hline Sample 3a & $\begin{array}{l}\text { Surface Seawater } \\
\left(36^{\circ} 50^{\prime} \mathrm{N}, 122^{\circ} 00^{\prime} \mathrm{W}\right)\end{array}$ & & & & \\
\hline Sample 3b & $\begin{array}{l}\text { Surface Seawater } \\
\left(36^{\circ} 50^{\prime} \mathrm{N}, 122^{\circ} 00^{\prime} \mathrm{W}\right)\end{array}$ & & & & \\
\hline Sample 3c & $\begin{array}{l}\text { Surface Seawater } \\
\left(36^{\circ} 50^{\prime} \mathrm{N}, 122^{\circ} 00^{\prime} \mathrm{W}\right)\end{array}$ & & & & \\
\hline Sample 4a & Wastewater Treatment Plant & & & & \\
\hline Sample 4b & Wastewater Treatment Plant & & & & \\
\hline Sample 4c & Wastewater Treatment Plant & & & & \\
\hline
\end{tabular}

